\title{
Quasi In-Situ Study on Microstructure Evolution of Al 2014 Alloy during Thermal Deformation and Following Solution Treatment
}

\author{
Hailong Cao ${ }^{1}$, Yuxing Tian ${ }^{*}$, Ningjie Gu${ }^{1}$, Lifang Chen², Cheng Liu ${ }^{1}$ \\ ${ }^{1}$ Chinalco Materials Application Research Institute, Beijing, China \\ ${ }^{2}$ Southwest Aluminum (Group) Co., Ltd., Chongqing, China \\ Email: *yxtiannin@163.com
}

How to cite this paper: Cao, H.L., Tian, Y.X., Gu, N.J., Chen, L.F. and Liu, C. (2019) Quasi In-Situ Study on Microstructure Evolution of Al 2014 Alloy during Thermal Deformation and Following Solution Treatment. Journal of Materials Science and Chemical Engineering, 7, 24-31.

https://doi.org/10.4236/msce.2019.78004

Received: April 26, 2019

Accepted: August 9, 2019

Published: August 12, 2019

\begin{abstract}
Microstructure evolution of 2014 aluminum alloy was studied by hot compression deformation at $410^{\circ} \mathrm{C}$ to $470^{\circ} \mathrm{C}$ and strain rates of $0.07 \mathrm{~s}^{-1}$ to $0.53 \mathrm{~s}^{-1}$, to provide manufacturing references for aluminum plate. The deformation temperature and especially strain rate ranges were chosen very close to the actual processing condition. The results show that the stress-strain curves display a stable flow at the given deformation conditions, corresponding a dominant microstructure evolution behavior of dynamic recovery (DRV) and few dynamic recrystallization (DRX). After solution treated at $502^{\circ} \mathrm{C}$ for 3 hours, quasi in-situ observation shows that static recrystallization (SRX) develop typical fine grains with several microns at grain boundaries, while static recovery (SRV) dominants the microstructure evolution during the soaking time, leading to a similar microstructure to that of the as-deformed. The average low angle grain boundaries $\left(\mathrm{L}_{\mathrm{AGBs}}\right)$ and high angle grain boundaries $\left(\mathrm{H}_{\mathrm{AGBs}}\right)$ display weak differences between as-deformed and solution treated specimens, which reveals a good thermal stability of microstructure for 2014 alloy. However, the deformation at the lower temperature has an obvious trend to induce SRX during solution soaking.
\end{abstract}

\section{Keywords}

2014 Aluminum Alloy, Microstructure Evolution, Recrystallization, Misorientation Distributions

\section{Introduction}

Thermo mechanical processing of metallic materials, accompanied by dynamic 
recovery (DRV) and dynamic recrystallization (DRX), is an effective method to modify microstructure. For most aluminum alloys, solution treatment and artificial aging is needed after thermal mechanical processing to obtain reasonable properties. Therefore, the final microstructure is controlled by both hot deformation process and solution treatment, corresponding to microstructural dynamic and static evolution. In order to achieve the better performance of metallic materials, manufacturers pay more and more attention to the continuous microstructure evolution from the previous process to the following process.

2014 aluminum alloy is an important structural material applied widely in the fields of aerospace and civil engineering, due to its high strength, good plasticity and high temperature stability [1] [2]. Also, this alloy has excellent forge ability and can be used for complex components such as aircraft joint with thin rib. Most of the previous studies [3] [4] investigated on its hot deformation processing and heat treatment, but the seldom focused on the continuous microstructure evolution from thermal mechanical processing to the following solution treatment. In this study, quasi in-situ observation was adapted to analyze the details of microstructure evolution from hot compression to solution treatment, and to supply processing references for aluminum plates.

\section{Materials and Experiment}

The 2014 aluminum alloy ingot used in the experiment was fabricated by direct chill casting. The main element contents are $4.4 \% \mathrm{Cu}, 0.5 \% \mathrm{Mg}, 0.8 \% \mathrm{Si}$ and $0.8 \% \mathrm{Mn}$. Cylindrical sample of $\Phi 10 \mathrm{~mm} \times 15 \mathrm{~mm}$ were cut from the homogenized ingot and compressed uniaxially using Gleeble 1500. The compression was conducted at strain rates of $0.07 \mathrm{~s}^{-1}, 0.27 \mathrm{~s}^{-1}$ and $0.53 \mathrm{~s}^{-1}$, and temperature of $410^{\circ} \mathrm{C}, 430^{\circ} \mathrm{C}, 450^{\circ} \mathrm{C}, 470^{\circ} \mathrm{C}$. The strain rates are chosen to very close to actual thermal deformation velocity of aluminum plates. Prior to the test, the samples were heated to the targeted temperatures and then held for 3 minutes to ensure temperature homogeneity. During the compression, the instant temperature was measured by thermocouples welded to the center area of the sample surface. Nickel powder was daubed on the two end surfaces of the sample to reduce friction. The height reduction is $70 \%$, corresponding to the true strain of 1.2. The compressed specimens were water cooled and then sectioned along the compression axis. As-deformed specimens was examined firstly, and then sealed into tube full of argon to solution treatment at $502^{\circ} \mathrm{C}$ for 3 hours. In order to observe the same position of the both microstructures of as-deformed and solution treated, the as-deformed specimens were marked by hardness pits and remain during the following microstructure examine.

JEOL 7800F scanning electron microscope with electron back-scattering diffraction (EBSD) system was used to investigate the detailed substructure characteristics. The EBSD samples were obtained by mechanical grinding and electrochemical polishing. 


\section{Results and Analysis}

\subsection{True Stress-Strain Curves}

Figure 1 shows the true stress-strain curves of 2014 aluminum alloy suffered hot compression deformation. These curves show the similar shapes being stable flow, and only slight hardening appears with the strain rate increasing. Stable flow generally can be considered as a balance between dislocation multiplication and dislocation recovery [5] [6] [7]. With strain rate increasing, increased velocity of dislocation multiplication lead to a quick hardening. Inversely, the shorter deformation time is not enough for microstructure evolution to consume the interior energy [8]. It should be noted that although the strain rate range of 0.07 $\mathrm{s}^{-1}-0.53 \mathrm{~s}^{-1}$ is so narrow, the flow stress increase obviously from $46-63 \mathrm{MPa}$ for $0.07 \mathrm{~s}^{-1}$, to $62-78 \mathrm{MPa}$ for $0.53 \mathrm{~s}^{-1}$. Figure 1 (d) shows the relationship between strain rate and flow peak stress, where the strain rate sensitivity value is 0.1 0.15 . It is revealed that although this value slightly lower than the general value of 0.3 , deformation resistance should be pay more attention during the actual thermal mechanical process. It is known that different matches of temperature and strain rate can obtain the same flow stress, but corresponding to the different microstructures. So the examination of the deformation microstructure is more important for choosing the reasonable thermal processing parameters.

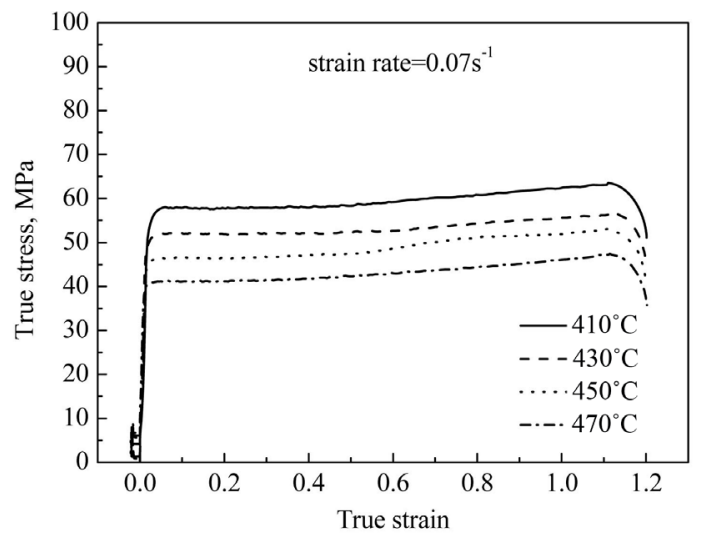

(a)

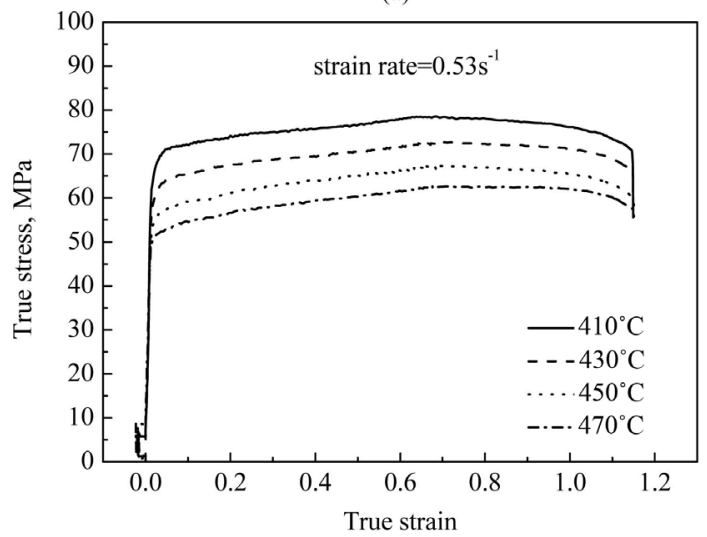

(c)

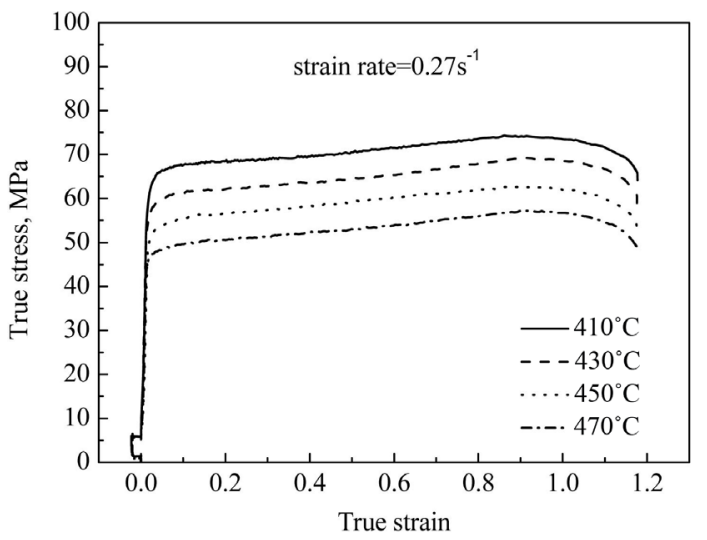

(b)

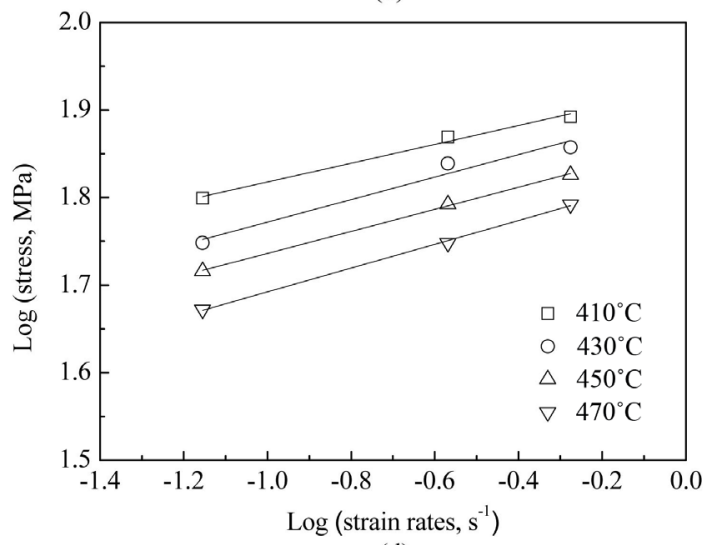

(d)

Figure 1. True stress-strain curves ((a)-(c)) and the relationship between flow stress and strain rate (d). 


\subsection{Microstructure Evolution}

Figure 2 shows the EBSD images of the microstructure deformed at $410^{\circ} \mathrm{C}$, strain rate of $0.07 \mathrm{~s}^{-1}$ and $0.53 \mathrm{~s}^{-1}$, as well as solution treated. Crystal orientation is marked by the inset color code, and high angle $\left(>15^{\circ}\right)$ and low angle $\left(\leq 15^{\circ}\right)$ grain boundaries are indicated by black line and white line, respectively. At this lower temperature of $410^{\circ} \mathrm{C}$, almost no differences are observed for the strain rate of $0.07 \mathrm{~s}^{-1}$ and $0.53 \mathrm{~s}^{-1}$ (Figure 2(a) and Figure 2(c)). Original grains are pancaked and the boundaries became serrate. Obvious characteristic is that new grains with several microns appear in the original boundaries, especially at triple junctions. These new developed grains are in accordance with the dynamic recrystallization (DRX) [7] [8] [9]. The colour difference of the EBSD images, in the interior of the pancake-shaped grains, reveals the accommodated lattice distortion induced by strain especially near to grain boundaries. It is clear that these deformed microstructures display a typical plasticity deformation dominated by dynamic recovery (DRV), while DRX is minimal.

Quasi in-situ observation is carried out for the deformed specimens after solution treatment at $502^{\circ} \mathrm{C}$ for 3 hours (Figure 2(b) and Figure 2(d)). The microstructures keep a similar overall morphology to the deformed microstructures, except three noticeable characteristics. Firstly, the small sized DRX grains grow to a certain extent, even crystal merging for different orientations, indicated by black circle in Figure 2(b) and Figure 2(d). Secondly, new DRX grains develop at tirple junctions with high storage energy, noted by the white circle. In addition, the lattice distortion indicated by color gradient has faded and evolved into regular sub-grain boundaries. These three characteristics, including the grain

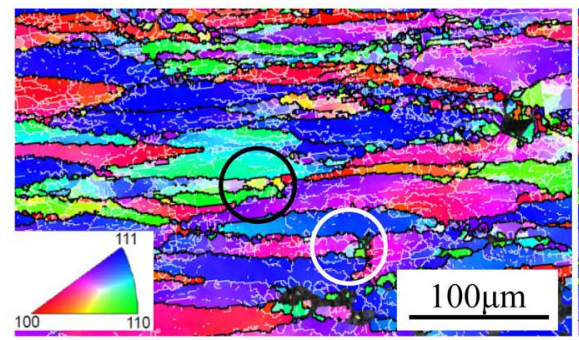

(a)

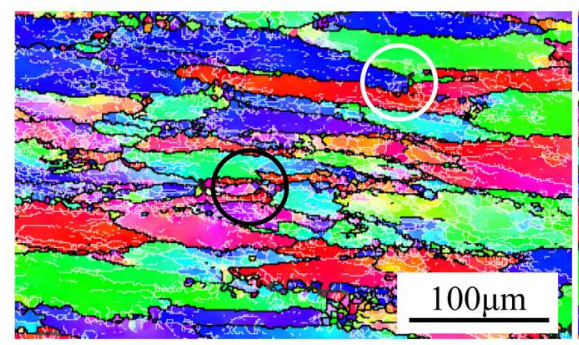

(c)

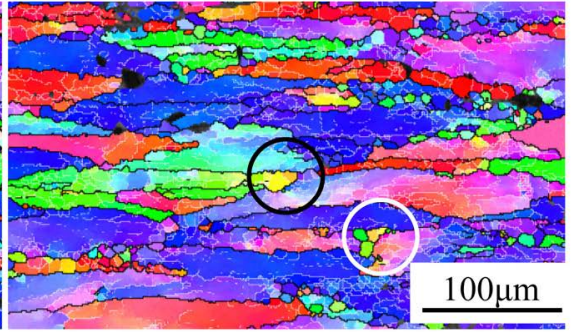

(b)

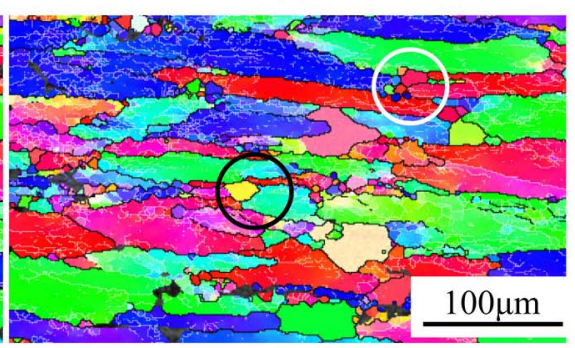

(d)

Figure 2. EBSD images of 2014 alloy deformed at $410^{\circ} \mathrm{C}$ and strain rate of $0.07 \mathrm{~s}^{-1}$ (a) and then solution treated (b); and deformed at $410^{\circ} \mathrm{C}$ and strain rate of $0.53 \mathrm{~s}^{-1}$ (c) and then solution treated $(\mathrm{d})$. 
merging, the formation of new DRX grains and the changes of lattice distortion, are all the ways for microstructure to consume deformable storage energy. Giving a brief summary, during the solution soaking at $502^{\circ} \mathrm{C}$ for 3 hours, static recrystallization (SRX) is the main evolution mechanism.

Figure 3 shows the EBSD images of the microstructure deformed at $470^{\circ} \mathrm{C}$, strain rate of $0.07 \mathrm{~s}^{-1}$ and $0.53 \mathrm{~s}^{-1}$, as well as solution treated. At this higher temperature of $470^{\circ} \mathrm{C}$, the quantity of new DRX grain decrease comparing with that of deformed at $410^{\circ} \mathrm{C}$, but the grain size is relatively large due to the higher deformation temperature. Typical DRX grains are noted by the black circle in Figure 3(a) and Figure 3(c). In this case, DRV is more enhanced no matter strain rate $0.07 \mathrm{~s}^{-1}$ or $0.53 \mathrm{~s}^{-1}$.

However, only two characteristics are observed after solution soaking. The merging of DRX grain noted by black circle in Figure 3(b) and Figure 3(d), and the changes of lattice distortion still happened similarly with that of deformed at $410^{\circ} \mathrm{C}$, while the new grains induced by SRX are not observed even at triple junction. This means deformation temperature is the most important factor for the recrystallization at the deformation parameters used in present study.

\subsection{Misorientation Distribution}

In order to analyze quantitatively the characteristics of sub-structure evolution, misorientation distribution is show in Figure 4. The deformed and solution treated microstructure were analyzed by calculating the fraction of low angle grain boundaries $\left(\mathrm{F}_{\mathrm{LABs}}\right)$, average misorientation angles of low angle grain boundary $\left(\theta_{\mathrm{LABs}}\right)$ and high angle grain boundaries $\left(\theta_{\mathrm{HABs}}\right)$, and the result listed in $\mathrm{Ta}$ ble 1. Firstly, the higher strain rate of $0.53 \mathrm{~s}^{-1}$ leads to the higher $\mathrm{F}_{\mathrm{LABs}}, 71 \%$ and

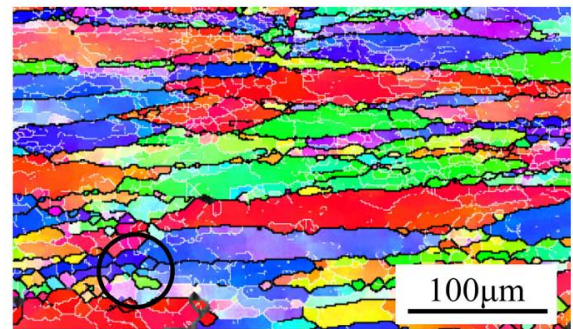

(a)

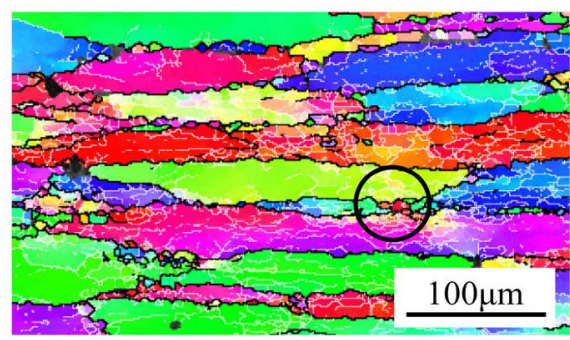

(c)

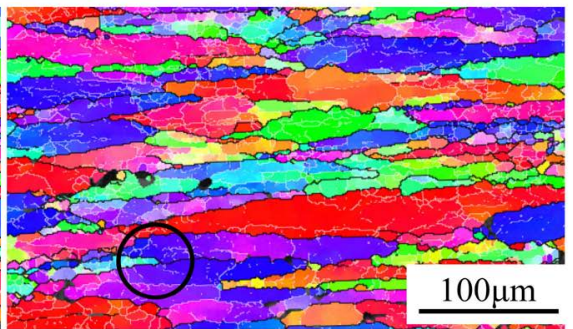

(b)

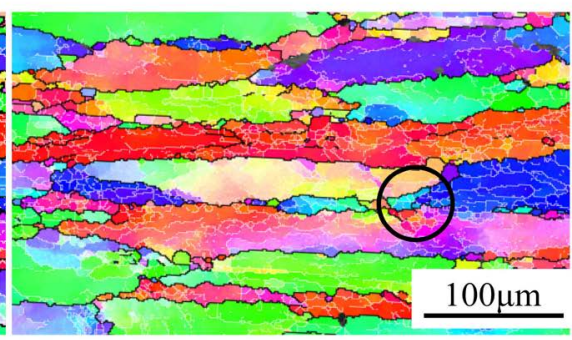

(d)

Figure 3. EBSD images of 2014 alloy deformed at $470^{\circ} \mathrm{C}$ and strain rate of $0.07 \mathrm{~s}^{-1}$ (a) and then solution treated (b); and deformed at $470^{\circ} \mathrm{C}$ and strain rate of $0.53 \mathrm{~s}^{-1}$ (c) and then solution treated $(\mathrm{d})$. 


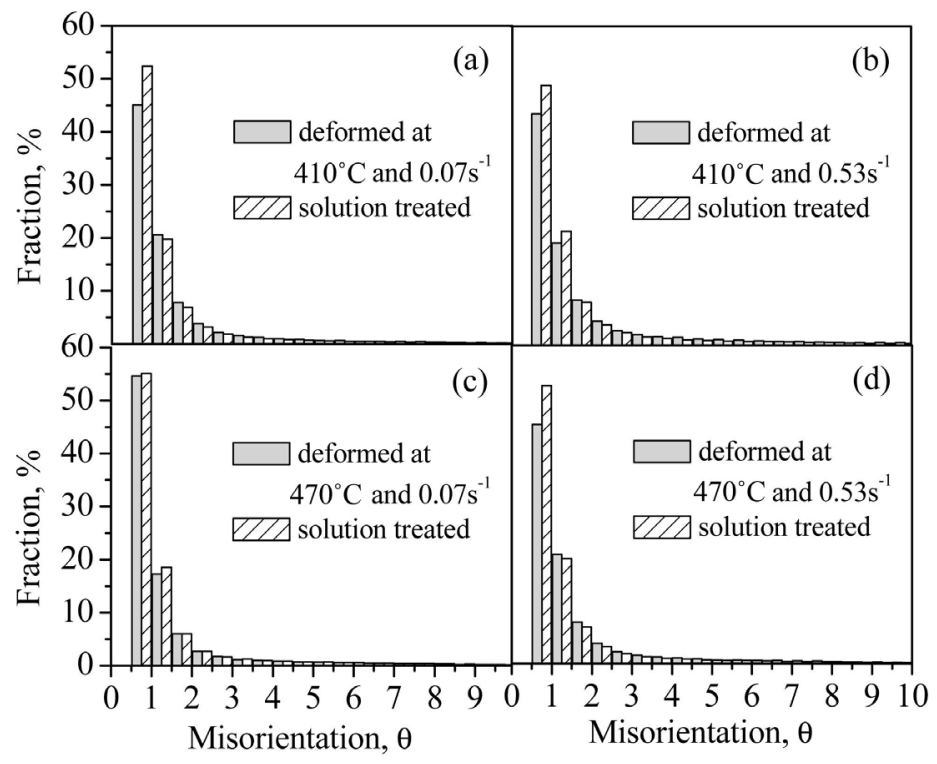

Figure 4. Misorientation distributions of 2014 alloy deformed at different conditions (gray bars) and then solution treated (shadow bars).

Table 1. Calculated $\mathrm{F}_{\mathrm{LABs}}, \theta_{\mathrm{LABs}}$ and $\theta_{\mathrm{HABs}}$ of the alloy deformed and solution treated.

\begin{tabular}{cccccccc}
\hline & & \multicolumn{3}{c}{ Deformed } & \multicolumn{3}{c}{ Solution treated } \\
\cline { 3 - 8 } & & $\mathrm{F}_{\mathrm{LABs}}$ & $\theta_{\mathrm{LABs}}$ & $\theta_{\mathrm{HABs}}$ & $\mathrm{F}_{\mathrm{LABs}}$ & $\theta_{\mathrm{LABs}}$ & $\theta_{\mathrm{HABs}}$ \\
\hline \multirow{3}{*}{$410^{\circ} \mathrm{C}$} & $0.07 \mathrm{~s}^{-1}$ & $65 \%$ & 5.1 & 42.3 & $66 \%$ & 4.9 & 43.0 \\
& $0.53 \mathrm{~s}^{-1}$ & $71 \%$ & 5.1 & 39.5 & $72 \%$ & 4.9 & 42.1 \\
& $0.07 \mathrm{~s}^{-1}$ & $63 \%$ & 5.3 & 40.8 & $68 \%$ & 5.3 & 41.5 \\
$470^{\circ} \mathrm{C}$ & $0.53 \mathrm{~s}^{-1}$ & $72 \%$ & 5.1 & 38.8 & $76 \%$ & 4.9 & 39.3 \\
\hline
\end{tabular}

$72 \%$, comparing with $65 \%$ and $63 \%$ for strain rate of $0.07 \mathrm{~s}^{-1}$. As such, the $\theta_{\mathrm{HABs}}$ is relatively lower for the higher strain rate of $0.53 \mathrm{~s}^{-1}$. Secondly, the solution soaking enhances the microstructure static recovery and leads to a weak increasing in $\mathrm{F}_{\mathrm{LABs}}$. Generally speaking, the sub-crystalline polygonization means a decrease in the fraction of low angle boundaries. In this case, the lattice distortion with misorientation angle of below $2^{\circ}$ is not considered. In fact, abundant of lattice distortion with small misorientation angle less than $2^{\circ}$ is beyond the detectable limitation of the EBSD analysis. These lattice distortions probably transform to the low angle grain boundaries, which leads to the increased FLABs value.

\subsection{Discussion}

In present study, the compression temperature range of $410^{\circ} \mathrm{C}-470^{\circ} \mathrm{C}$ and train rates of $0.07 \mathrm{~s}^{-1}-0.53 \mathrm{~s}^{-1}$ are chosen to very close to the actual thermal deformation parameters, in order to refine the actual thermal deformation processing. Although stable flow has displayed the good deformation ability of this alloy, slight differences of temperatures and strain rates induce the different substruc- 
ture, especially after solution treatment. The most obvious is that the specimen deformed at the lower temperature of $410^{\circ} \mathrm{C}$ has the further trend to recrystallization after solution soaking at $502^{\circ} \mathrm{C}$ for 3 hours. However, the higher deformation temperature of $470^{\circ} \mathrm{C}$ is more inclined to obtain a uniform microstructure with the lower deformation storage energy. Essentially, plastic flow ability of metallic materials decreases with deformation temperature decreasing [10] [11], which is the dominant factor for strain concentration. So the higher deformation storage energy releases by the way to form new grains and alleviate lattice distortion. Generally, the solution soaking time of 3 hours is enough for the conventional forgings, plates and extrusions. The final microstructure controlling of these work pieces are suggested to pay more attention to the thermal mechanical process.

\section{Conclusions}

The continuous microstructure evolution of 2014 aluminum alloy is studied by hot compression deformation at the relative narrow temperature range of $410^{\circ} \mathrm{C}$ - $470^{\circ} \mathrm{C}$ and strain rate of $0.07 \mathrm{~s}^{-1}-0.53 \mathrm{~s}^{-1}$, to provide manufacturing suggestions for aluminum plate.

1) At the given deformation conditions, stable deformation flow corresponds to the microstructure evolution behavior of dominant dynamic recovery (DRV) and few dynamic recrystallization (DRX).

2) After solution treated at $502^{\circ} \mathrm{C}$ for 3 hours, static recrystallization (SRX) develop typical fine grains with several microns at grain boundaries, while static recovery (SRV) dominants the microstructure evolution during the soaking time, leading to a similar microstructure to that of the as-deformed.

3) The average low angle grain boundaries $\left(\mathrm{L}_{\mathrm{AGBs}}\right)$ and high angle grain boundaries $\left(\mathrm{H}_{\mathrm{AGBs}}\right)$ display weak differences between as-deformed and solution treated specimens, which reveals a good thermal stability of microstructure for 2014 alloy. However, the deformation at the lower temperature has an obvious trend to induce static recrystallization during solution soaking.

\section{Conflicts of Interest}

The authors declare no conflicts of interest regarding the publication of this paper.

\section{References}

[1] Joshi, A., Kumar, N., Yogesha, K.K., et al. (2016) Mechanical Properties and Microstructural Evolution in Al 2014 Alloy Processed Through Multidirectional Cryoforging. Journal of Materials Engineering \& Performance, 25, 3031-3045. https://doi.org/10.1007/s11665-016-2126-0

[2] Ramanjaneyulu, K., Madhusudhan, R.G. and Hina, G. (2015) Optimization of Process Parameters of Aluminum Alloy AA 2014-T6 Friction Stir Welds by Response Surface Methodology. Defence Technology, No. 11, 209-219. https://doi.org/10.1016/j.dt.2015.03.003 
[3] Dhal, A., Panigrahi, S.K. and Shunmugam, M.S. (2015) Influence of Annealing on Stain Hardening Behaviour and Fracture Properties of a Cryorolled Al 2014 Alloy. Materials Science \& Engineering A, 645, 383-392. https://doi.org/10.1016/j.msea.2015.08.020

[4] Johansson, M., Hörnqvist, M. and Karlsson, B. (2006) Influence of Temperature and Strain Rate on the Plastic Deformation of Two Commercial High Strength Al Alloys. Materials Science Forum, 519-521, 841-846. https://doi.org/10.4028/www.scientific.net/MSF.519-521.841

[5] Shi, C.J. and Chen, X.G. (2012) Hot Deformation Behavior and Microstructural Evolution of Homogenized 7150 Aluminum Alloys Micro-Alloyed with $\mathrm{Zr}$ and V. 13 th International Conference on Aluminum Alloys (ICAA13), 1599-1605.

https://doi.org/10.1002/9781118495292.ch240

[6] Fan, W., Kashyap, B.P. and Chaturvedi, M.C. (2001) Effects of Strain Rate and Test Temperature on Flow Behaviour and Microstructural Evolution in AA 8090 Al-Li alloy. Materials Science and Technology, 17, 431-438. https://doi.org/10.1179/026708301101510005

[7] Tian, Y.X. and Hao, Y.L. (2016) Microstructure Evolution of a Multifunctional Titanium Alloy. Shape Memory \& Superelasticity, 2, 160-170.

https://doi.org/10.1007/s40830-016-0065-0

[8] Tian, Y.X., Wang, G., Yu, S., et al. (2015) Microstructure Characteristics and Strain Rate Sensitivity of a Biomedical Ti-25Nb-3Zr-3Mo-2Sn Titanium Alloy during Thermomechanical Processing. Journal of Materials Science, 50, 5165-5173. https://doi.org/10.1007/s10853-015-9061-6

[9] Yang, Q., Deng, Z., Zhang, Z., et al. (2016) Effects of Strain Rate on Flow Stress Behavior and Dynamic Recrystallization Mechanism of Al-Zn-Mg-Cu Aluminum Alloy during Hot Deformation. Materials Science \& Engineering A, 662, 204-213. https://doi.org/10.1016/j.msea.2016.03.027

[10] Sakai, T., Miura, H., Goloborodko, A., et al. (2009) Continuous Dynamic Recrystallization during the Transient Severe Deformation of Aluminum Alloy 7475. Acta Materialia, 57, 153-162. https://doi.org/10.1016/j.actamat.2008.09.001

[11] Huang, H., Jiang, F., Zhou, J., et al. (2015) Hot Deformation Behavior and Microstructural Evolution of As-Homogenized Al-6Mg-0.4Mn-0.25Sc-0.1Zr Alloy during Compression at Elevated Temperature. Journal of Alloys \& Compounds, 644, 862-872. https://doi.org/10.1016/j.jallcom.2015.05.048 